\title{
Midgut proteome of an argasid tick, Ornithodoros erraticus: a comparison between unfed and engorged females
}

\author{
Ana Oleaga*, Prosper Obolo-Mvoulouga, Raúl Manzano-Román and Ricardo Pérez-Sánchez
}

\begin{abstract}
Background: The argasid tick Ornithodoros erraticus is the vector of African swine fever virus and of several Borrelia species that cause human relapsing fever in the Iberian Peninsula. The tick midgut is part of the ectoparasite-host interface and expresses proteins that are vital for the survival of the tick. Midgut proteins are therefore potential targets for drug and/or vaccine design aimed at the development of new strategies for tick control. Thus, the aim of this work was the characterization of the proteome of the $O$. erraticus midgut before and after a blood meal trying to elucidate the induced changes upon blood feeding.
\end{abstract}

Methods: Midgut tissues from unfed and engorged O. erraticus females were dissected and proteins were fractionated by centrifugation and SDS-PAGE, and the corresponding gel pieces analysed by LC-MS/MS. The identified proteins were classified according to their Protein Class and Molecular Function and the differences between fed and unfed specimens were analysed.

Results: Overall 555 tick proteins were identified: 414 in the midgut of the unfed specimens and 376 in the fed specimens, of which 235 were present in both groups. The proteins with catalytic, binding and structural functions were the most numerous and abundant, consistent with their role in the intracellular processing of the blood meal. The analysis of some groups of proteins putatively involved directly in blood meal digestion, including protein digestion (peptidase activity), iron metabolism, enzymes involved in oxidative stress and detoxification and membrane traffic and transport proteins, detected some differences between the fed and unfed ticks

Conclusions: This work reports for the first time the collection and analysis of the midgut proteome of an argasid tick species and provides molecular information about the argasid machinery involved in blood digestion. This information represents a starting point for the identification and selection of new targets for the development of alternative control strategies.

Keywords: Ornitodoros erraticus, Soft tick, Midgut, Proteome, Blood digestion

\section{Background}

Ticks are blood-sucking arthropods that belong to two large families, Ixodidae (hard ticks) and Argasidae (soft ticks). They are of huge medical and veterinary importance not only because of the direct harm they cause to the host but also because they are the vectors of a large number of pathogens that affect livestock, pets, and humans $[1,2]$. Among the argasid ticks, several species of the genus Ornithodoros are of special importance

\footnotetext{
* Correspondence: ana.oleaga@irnasa.csic.es

Parasitology Laboratory, Instituto de Recursos Naturales y Agrobiología de Salamanca (IRNASA, CSIC), Cordel de Merinas, 40-52, 37008 Salamanca, Spain
}

because they transmit pathogens that cause severe diseases such as human Tick-borne relapsing fever and African swine fever. Specifically, Ornithodoros erraticus is the main vector of these diseases in the Iberian Peninsula [3, 4].

The presence of this argasid in domestic and peridomestic environments contributes to the persistence of these diseases in endemic areas and also poses a constant threat for reintroduction, spread, and long term maintenance in areas from where they have been eradicated or where they have never existed. Thus, the prevention and control of these diseases would require the 
elimination of this argasid from synanthropic environments [5]. The application of chemical acaricides for the control of O. erraticus has severe drawbacks (acaricide resistance and contamination of the environment and animal products) and has proved to be inefficient [6-9]. These problems have stimulated the development of alternative methods for the control of this argasid tick, among which vaccines have emerged as the most promising, in particular those based on the concealed antigens of the tick midgut $[1,5]$. In this sense, previous work carried out by our team reported immunization trials using a midgut surface exposed antigen in O. erraticus capable of significantly blocking feeding and reproduction performance in females and inducing lethal damages in the gut of nymphs fed on vaccinated animals $[10,11]$. It was noted that such damages were mediated by host complement factors ingested with blood, in a similar way to that observed in the efficient hard tick vaccines based on the midgut Bm86 antigen [12, 13]. The O. erraticus antigen responsible for the observed protection remains to be identified, but these findings indicate that the midgut of argasid ticks could be an important source of candidate antigens for vaccines, in agreement with what has been proposed for ixodids by other authors $[9,14]$.

The tick midgut is the organ responsible for digesting the host's blood and for absorbing the nutrients necessary for its survival and reproduction. Additionally, the tick midgut epithelium is a major physical barrier between the tick and the host defense mechanisms and also the initial site for pathogen infection being thus an important target for pathogen transmission blockage [15]. Accordingly, the midgut constitutes an important part of the host-tickpathogen interface expressing proteins involved in vital functions for the tick and for tick invasion by pathogens ingested with the blood.

Unlike blood-feeding insects, which feed and digest blood rapidly in the neutral $\mathrm{pH}$ of the gut lumen, tick feeding is a slower process, and digestion takes place in the acidic intracellular compartment of the gut epithelium [16]. Moreover, the physiology of feeding and blood digestion differs substantially between hard and soft ticks [17-19]. In most argasid species, nymphs and adults take their blood meal rapidly, within minuteshours, and then drop off the host. By contrast, ixodid ticks remain attached to their vertebrate host for long periods and feed continuously for days or even weeks [17].

In ixodid ticks, the digestive system, the blood digestion process and the digestion-associated histological modifications of the midgut epithelium have been addressed in many studies. Such studies have provided a solid understanding of how this tick family handles blood meals [16-20]. More recently, our understanding of these processes at molecular level has been substantially improved owing to the analysis of the midgut transcriptomes and proteomes of several ixodid species [21-26].

By contrast, the physiology and biochemistry of blood digestion in argasid ticks have been little studied and the information available is essentially limited to O. moubata [27-29]. To date, no argasid midgut proteome or transcriptome has been published.

In light of the foregoing, investigation of the O. erraticus midgut proteome might provide an in-depth understanding of the key cellular processes of the digestive physiology of argasids, affording valuable information about potential targets for drug and/or vaccine design aimed at the development of new strategies for tick control [23].

Thus, the aim of this work was the characterization of the proteome of the $O$. erraticus midgut before and after a blood meal trying to elucidate the induced changes upon blood feeding. To achieve this goal, midgut tissues from unfed and engorged $O$. erraticus females were dissected and proteins were fractionated by centrifugation and SDS-PAGE, and the corresponding gel pieces analysed by LC-MS/MS. Altogether, in fed and unfed ticks we identified 555 tick proteins, which were classified according to their Protein Class and Molecular Function. The differences between fed and unfed specimens are discussed.

\section{Methods}

\section{Ticks and tick material}

The colony of $O$. erraticus ticks is maintained in the laboratory of Animal Parasitology (IRNASA, CSIC) and was established from specimens captured in Salamanca province (western Spain). Ticks are fed regularly on rabbits and kept in a culture chamber at $28{ }^{\circ} \mathrm{C}, 85 \%$ relative humidity and a $12 \mathrm{~h}$ light-dark cycle.

\section{Ethical approval}

Tick maintenance and all animal manipulation were done according to the rules from the Ethical and Animal Welfare Committee of the institution where the experiments were conducted (IRNASA, CSIC), following the corresponding EU rules and regulations.

\section{Preparation of midgut protein extracts for proteomic analyses}

Midgut extracts were prepared from unfed females (unfed group) and from engorged females at $48 \mathrm{~h}$ post-feeding (fed group). To accomplish this, the ticks were dissected in sterile phosphate buffered saline (PBS) $\mathrm{pH} 7.4$ at $4{ }^{\circ} \mathrm{C}$ and the midguts were removed and rinsed several times in PBS to eliminate host blood [10]. Batches of 50 midguts were suspended in fresh PBS containing a cocktail of proteinase inhibitors (Roche Diagnostics), homogenized on ice using an Ultra-Turrax T10 disperser (IKA-Werke), and then sonicated 6 times for $30 \mathrm{~s} /$ 
each. Tissue homogenates were centrifuged for $20 \mathrm{~min}$ at $10,000 \times \mathrm{g}$ and $4{ }^{\circ} \mathrm{C}$ to remove cellular debris, and the $10,000 \mathrm{xg}$ supernatants were recovered and centrifuged for $1 \mathrm{~h}$ at $100,000 \times \mathrm{g}$ and $4{ }^{\circ} \mathrm{C}$. These new supernatants were recovered and named S- 0 and S-1, corresponding to the soluble fractions of midgut proteins from the unfed and fed ticks respectively. The pellets were re-suspended in PBS containing protease inhibitors and centrifuged once again for $1 \mathrm{~h}$ at $100,000 \times \mathrm{g}$ and $4{ }^{\circ} \mathrm{C}$. The resulting new pellets were recovered and named P- 0 and P-1, corresponding to the insoluble fractions of midgut proteins from unfed and fed ticks respectively. The protein concentrations in all these fractions were measured using the BCA Protein Assay Reagent kit (Thermo-Fisher). Samples were stored at $-20^{\circ} \mathrm{C}$.
Samples of $20 \mu \mathrm{g}$ from each fraction (S-0, S-1, P-0 and P-1) were mixed with $4 x$ Laemmli buffer [30], heated to $90{ }^{\circ} \mathrm{C}$ for $3 \mathrm{~min}$, and centrifuged at $10,000 \mathrm{xg}$ for $4 \mathrm{~min}$. The protein samples were then resolved by SDS-PAGE in 5-20\% gradient polyacrylamide gels and the gels were stained with Sypro Ruby (Bio-Rad) for protein visualization and image analysis (ChemiDoc System and Image Lab software, Bio-Rad) or with Coomassie Blue (Coomassie Blue R-25 $0.125 \%$, methanol $50 \%$, acetic acid $10 \%$ ) for LC-MS/MS analysis (see below).

In the Coomassie blue-stained gels, each lane (corresponding to S-0, S-1, P-0 and P-1) was sliced into 10 pieces (see Fig. 1), which were sent to the SCSIE_University of Valencia Proteomics Unit, belonging to the

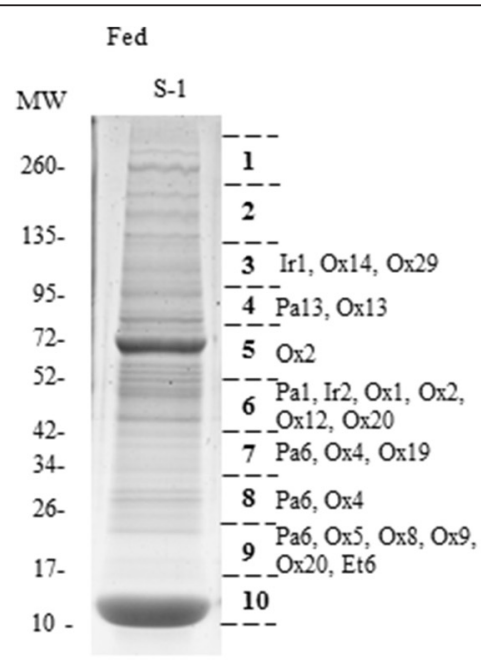

Unfed

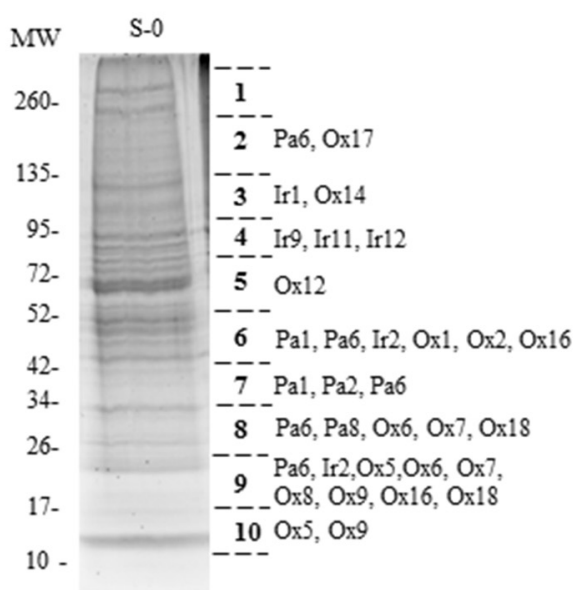

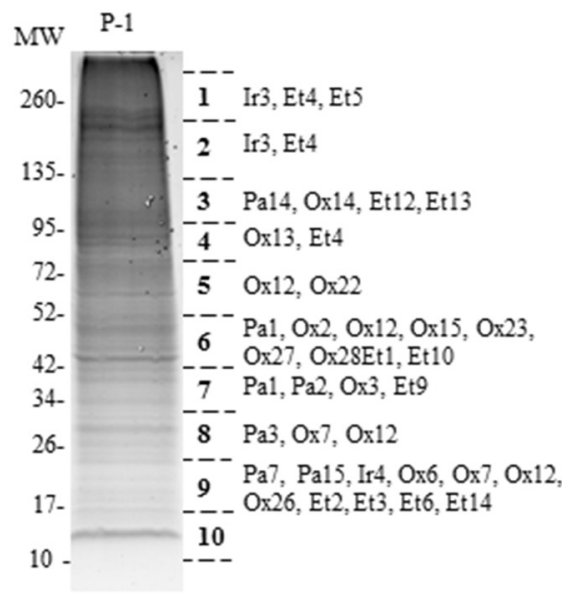

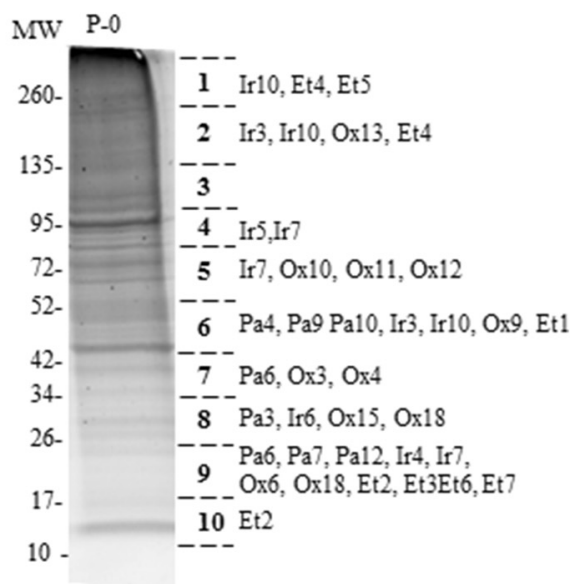

Fig. 1 Sypro Ruby-stained 5-20\% polyacrylamide gel showing the protein fractions obtained from midgut homogenates of fed and unfed Ornithodoros erraticus ticks. Gel lanes were sliced into the 10 pieces indicated on the right, and the resulting gel fragments were digested with trypsin and analyzed by LC-MS/MS for protein identification. Some of the most interesting proteins identified in each gel fragment are indicated using custom alphanumeric codes. A description of these codes can be found in Table 2. S-1 and P-1, supernatant and pellet from midgut homogenates of fed ticks. S-0 and P-0, supernatant and pellet from midgut homogenates of unfed ticks 
ISCIII ProteoRed Proteomics Platform (Spain), for mass spectrometry analyses and protein identification.

\section{In-gel enzymatic digestion and liquid chromatography and tandem mass spectrometry (LC-MS/MS)}

Each gel slice from the S-0, S-1, P-0 and P-1 fractions was subjected to enzymatic digestion and LC-MS/MS analysis. Briefly, the procedure was as follows: gel slices were conditioned with $50 \%$ acetonitrile, dried, and digested with sequencing-grade trypsin (Promega) (20 ng/ $\mu \mathrm{l}$ in $25 \mathrm{mM} \mathrm{NH}_{4} \mathrm{HCO}_{3}$ ) overnight at $37^{\circ} \mathrm{C}$. The reactions were stopped with $10 \%$ trifluoroacetic acid at a final concentration of $0.1 \%$, and the supernatants were filtered through a $0.22 \mu \mathrm{m}$ filter and dried by centrifugation in a vacuum. The concentration of peptides was estimated by UV spectrometry, assuming that a $1 \mathrm{mg} / \mathrm{ml}$ solution of proteins had an extinction coefficient of 1.1 absorbance units at $280 \mathrm{~nm}$. A BSA plug was analysed in the same way to control the digestion process.

The peptides extracted after in-gel digestion were resuspended in $5 \mu \mathrm{l}$ of $5 \%$ acetonitrile, $0.1 \%$ trifluoroacetic acid, and $5 \mu \mathrm{l}$ of the sample was loaded onto a trap column (NanoLC Column, $3 \mu \mathrm{C} 18-\mathrm{CL}, 350 \mu \mathrm{m} \times 0.5 \mathrm{~mm}$, Eksigen) and desalted with $0.1 \%$ trifluoroacetic acid at a flow rate of $3 \mu \mathrm{l} / \mathrm{min}$ for $5 \mathrm{~min}$. The peptides were then loaded onto an analytical column (LC Column, $3 \mu \mathrm{C} 18$ $\mathrm{CL}, 75 \mu \mathrm{m} \times 25 \mathrm{~cm}$, Eksigen) equilibrated in $5 \%$ acetonitrile and $0.1 \%$ formic acid. The peptides eluted were analysed with a nanoESI-Q-TOF mass spectrometer (5600 TripleTOF, ABSciex) in information-dependent acquisition mode, in which a 0.25 -s TOF MS scan from 350 to $1250 \mathrm{~m} / \mathrm{z}$ was performed, followed by 0.05 -s product ion scans from 100 to $1500 \mathrm{~m} / \mathrm{z}$ on the 50 most intense 2-5 charged ions.

\section{Database searching and protein identification}

Searches were performed in the NCBInr_Metazoa $(4,909,369$ sequences) and NCBI EST_Acari (2,476,050 sequences) databases using the Mascot v2.2 (Matrix Science) search engine. Database searching was initially done individually for each gel piece and then jointly for each sample by combining the spectra from the 10 gel pieces into which the same sample had been sliced.

For the Mascot searches, the peak lists were generated directly from QSTAR wiff files by Mascot Daemon v. 2.2.2 (Matrix Science) with Sciex Analyst import filter options using the default parameters. Databases were searched using the following parameters: tryptic specificity, allowing one missed cleavage and a tolerance in the mass measurement of $70 \mathrm{ppm}$ in MS mode and 0.6 Da for MS/MS ions. The carbamidomethylation of Cys was set as a fixed modification, and Met oxidation and Asn/Gln deamidation were set as variable modifications. The significance threshold was set at 0.05 and only proteins with at least two unique significant peptides were selected and shown in the results.

The relative abundance of a protein in the sample was quantified using the protein abundance index (PAI), which is defined as the number of observed peptides in the experiment divided by the number of observable tryptic peptides for each protein within a given mass range of the mass spectrometer employed [31]. The PAI was modified exponentially to give emPAI, the exponential form of PAI minus one, which is directly proportional to the protein content in a sample [32]. For estimating the relative abundance in a physiological state (fed or unfed) of proteins identified in the soluble and insoluble fractions the corresponding emPAI values were added.

In the Results section, redundant identifications were eliminated from the lists of identified proteins, in each case choosing the protein hit with the highest score. Keratins and other possible contaminants such as porcine trypsin were also excluded from the lists of proteins identified. In these results we added the additional identifications obtained in the EST_Acari database searches to the list of non-redundant proteins identified in the NCBInr_Metazoa database.

\section{Functional annotation and classification}

Protein classification was performed according to the Gene Ontology (GO) hierarchy, using the Universal Protein Resource (UniProt) retrieval system (http:// www.uniprot.org/) and the PANTHER (Protein ANalysis THrough Evolutionary Relationships) Classification System (http://www.pantherdb.org/) [33]. The "ID mapping" module for the UniProt system was used to transform the GI number to UniProt code, standardize protein symbols, and associate them with corresponding gene names, gene ontology categories and IDs, molecular function, subcellular location and biological process.

\section{Results}

\section{Midgut protein extracts}

Midguts from fed and unfed female ticks were homogenized and fractionated by centrifugation at 100,000 $\times \mathrm{g}$, obtaining two types of fractions: the fraction enriched in soluble proteins (supernatants S-0 and S-1) and the fraction enriched in insoluble membrane-associated proteins (pellets $\mathrm{P}-0$ and $\mathrm{P}-1$ ).

The proteins in each fraction were resolved by SDSPAGE (Fig. 1). All fractions showed complex band patterns that covered a broad range of molecular sizes and revealed evident differences in protein composition between unfed and fed ticks (i.e., band patterns in the range of $52 \mathrm{kDa}$ to $100 \mathrm{kDa}$ ). In the $\mathrm{S}-1$ soluble fraction, obtained from fed specimens, the two more intense bands at $70 \mathrm{kDa}$ and $15 \mathrm{kDa}$ corresponded to the host serum 
albumin and haemoglobin, respectively. Fig. 1 also shows some interesting proteins among those identified in the different gel fragments in which each fraction was divided (see below).

The reproducibility of the sample preparations and fractionations was checked in three different batches of midguts that always showed band patterns identical to their homologous one in Fig. 1 (not shown).

\section{Proteins identified}

In order to simplify the comparative study, we processed and analysed the Mascot results obtained from database searching with the combined spectra of the 10 gel slices from each fraction (S-0, P-0, S-1, P-1) (Fig. 1).

The results reported here refer to the identifications, on the basis of at least two significant peptides, performed with Mascot in the NCBInr_Metazoa and EST_Acari databases after removing redundancies and contaminants (Table 1). Since blood meal digestion in ticks is intracellular, all the fractions of tick midguts contained a mixture of tick proteins and host blood proteins. Thus, protein origin was assigned to the tick when the protein hit was from a tick, an arthropod or a nonmammalian vertebrate and to the host when the protein hit was from rabbit or any other mammalian species. Additional file 1: Table S1 and Additional file 2: Table S2 list the proteins of tick origin identified in unfed and fed $O$. erraticus females, respectively and Additional file 3: Table S3 lists the proteins of host origin. Additional file 4: Figure S1 represents the percentage of amino acid sequence coverage for all proteins identified in each fraction (supernatants and pellets).

Regarding the proteins of host origin, Table 1 and Fig. 2 show their number and ratio in each fraction. As expected, host proteins were more numerous in the samples from fed ticks (51 and $32 \%$, in S-1 and P-1, respectively) than in the homologous samples from unfed ticks (14.4 and $4.6 \%$, in S-0 and P-0, respectively). These host proteins were abundantly represented in all the fractions, as indicated by the sums of their emPAI values. This was particularly evident in the case of the S-1 fraction, where rabbit haemoglobin and albumin accounted for most of the total emPAI value (3723.2) of the host proteins identified in this fraction (Fig. 1, bands of 15 and $70 \mathrm{kDa}$, respectively). In the present work these host proteins were omitted from further characterization and analysis.

Regarding the tick proteins, the number of nonredundant proteins identified in the different fractions ranged between 141 and 330, showing the insoluble fractions P- 0 and P- 1 the highest values (Table 1, Additional file 1: Table S1 and Additional file 2: Table S2).

Proteomic analysis of the soluble fractions (S-0 and S-1) from unfed and fed ticks allowed the identification of a total of 223 non-redundant tick proteins: 82 only in the gut from unfed ticks; 65 only in fed ticks, and 76 in both groups (Fig. 3a). In the insoluble fractions (P-0 and P-1), 438 non-redundant proteins were identified: 147 only in the gut from unfed ticks; 108 only in fed ticks, and 183 in both groups of ticks (Fig. 3a).

The tick proteins identified in each fraction were classified according to their molecular function using the UniProt tools. As can be seen in Fig 3b, the functional classification was very similar for all four samples, whose proteins were distributed in the following categories: catalytic, binding, structural, transporter, antioxidant, electron carrier, GDP-dissociation inhibitor, cytochrome oxidase, and receptor activity. In all fractions (S-0, S-1, $\mathrm{P}-0, \mathrm{P}-1)$, the most numerous proteins were those involved in catalytic (53.2 and 50.4 \% in S-0 and S-1; 37.9 and $29.9 \%$ in P-0 and P-1) and binding activities (40.5 and $41.1 \%$ in S-0 and S-1; 38.8 and $30.6 \%$ in P-0 and P-1). Structural proteins were also represented in all

Table 1 Number of unique proteins identified in the midgut fractions from Ornithodoros erraticus fasted females (unfed group) and from engorged females after $48 \mathrm{~h}$ post-feeding (fed group)

\begin{tabular}{|c|c|c|c|c|}
\hline & \multicolumn{2}{|l|}{ Unfed ticks } & \multicolumn{2}{|l|}{ Fed Ticks } \\
\hline & Soluble fraction (S-0) & Insoluble fraction (P-0) & Soluble fraction (S-1) & Insoluble fraction (P-1) \\
\hline Non-redundant proteins $\left(\mathrm{n}^{\circ}\right)$ : NCBI_Metazoa & 124 & 223 & 242 & 319 \\
\hline NCBI_EST_Acari & 138 & 284 & 138 & 261 \\
\hline Total non-redundant proteins & 185 & 346 & 292 & 429 \\
\hline Tick proteins $\left(n^{\circ}\right)$ & 158 & 330 & 141 & 291 \\
\hline$N^{\circ}$ of peptides & 585 & 1287 & 535 & 1120 \\
\hline emPAl & 72.7 & 229.5 & 62.39 & 203.41 \\
\hline Host proteins $\left(n^{\circ}\right)$ & 27 & 16 & 151 & 138 \\
\hline$N^{0}$ of peptides & 232 & 131 & 986 & 938 \\
\hline emPAl & 685.4 & 376.0 & 3723.2 & 626.3 \\
\hline
\end{tabular}




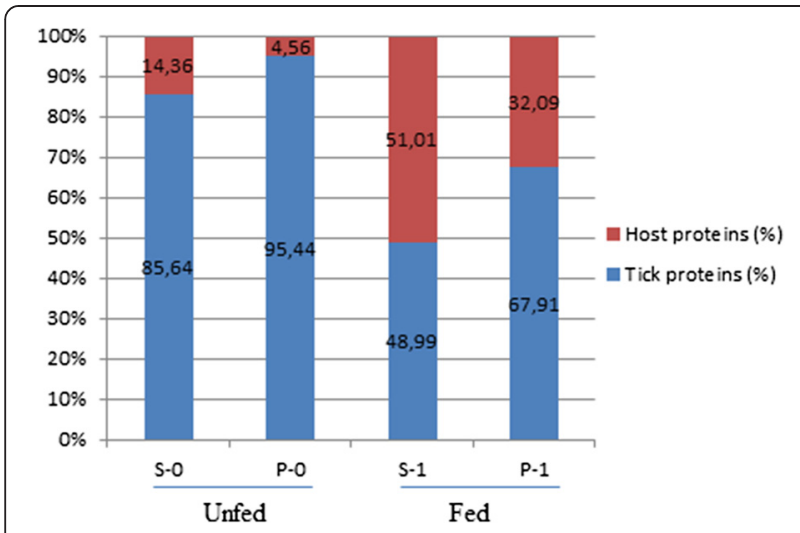

Fig. 2 Ratio of unique proteins of either tick or host origin identified in each fraction obtained from midgut homogenates. S-1 and $\mathrm{P}-1$, supernatant and pellet from midgut homogenates of fed ticks. S-0 and P-0, supernatant and pellet from midgut homogenates of unfed ticks

fractions, but they were twice more numerous in the insoluble than in the soluble fractions (20.0 and $21.6 \%$ in P-0 and P-1 versus 9.5 and $9.2 \%$ in S-0 and S-1). The remaining categories showed remarkably lower ratios in all fractions, except those classified as having an unknown molecular function, which ranged between 25.9 and $42.0 \%$ (Fig. 3b). The available GO data on Molecular Function, Biological Process and Cellular Component for each protein are included in Additional file 1: Table S1 and Additional file 2: Table S2.

\section{Comparative analysis of the proteins identified in the midgut of unfed and fed 0 . erraticus females}

In order to perform a comparative analysis of the proteins identified in the midgut from the fed and unfed ticks, the two fractions from the same experimental group were grouped and analysed together. Overall, 555 non-redundant midgut proteins were identified: 414 in unfed ticks, 376 in fed ticks, and 235 in both groups, unfed and fed (Fig. 4a).

The proteins identified in each physiological state, unfed and fed, were classified by "Protein Class" using the Panther Classification System, which allowed the categorization of 172 genes/proteins from the unfed ticks and 150 genes/proteins from the fed ticks (Fig. 4b). For both proteomes, unfed and fed, Panther generated very similar distributions, in which the proteins were grouped within the same 23 protein classes. The most numerous protein classes were nucleic acid binding (15.7\% in unfed and $20.7 \%$ in fed) and hydrolases (16.3\% in unfed and $14.0 \%$ in fed), followed by oxidoreductases (14.0\% in unfed and $13.3 \%$ in fed), transferases (12.8 \% in unfed and $12.7 \%$ in 12.7$)$, enzyme modulators (8.7\% in unfed and $9.3 \%$ in fed), cytoskeletal proteins $(9.3 \%$ in unfed and $8.0 \%$ in fed $)$, transporter $(6.4 \%$ in unfed and $7.3 \%$ in fed) and membrane traffic proteins ( $4.1 \%$ in unfed and $8.7 \%$ in fed). There were few differences in the protein class ratios between the fed and unfed ticks, being membrane traffic and nucleic acidbinding proteins more numerous in the midgut of the fed ticks.

Following this, the proteins identified only in unfed, only in fed and in both groups of ticks were analysed separately and categorized according to their "Molecular Function" using the tools available in the UniProt website (Fig. 5, Additional file 5: Table S4). This analysis revealed that the proteins involved in catalytic and binding activities were the most numerous and abundant proteins identified in the "only unfed" and "only fed" groups (Fig. 5a). The number of these catalytic and binding proteins was similar in both groups but the catalytic proteins were more abundant in the "only unfed" group (26.4 emPAI in unfed ticks versus 17.5 emPAI in fed ticks). Some additional differences were observed between both groups in the percentages of proteins with transporter $(11.0 \%$ only in fed versus $7.0 \%$ only in unfed) and structural activity (15.4\% only in fed versus $12.4 \%$ only in unfed), which were both more numerous in fed than in unfed ticks.

Regarding proteins identified simultaneously in unfed and fed ticks, the most numerous were those involved in binding, catalytic and structural functions. The main differences observed in this analysis were the higher abundance in unfed ticks of proteins with binding (105.8 emPAI in unfed versus 85.7 emPAI in fed) and transporter activity (12.8 emPAI in unfed versus 8.34 emPAI in fed) (Fig. 5b).

\section{Proteins involved in blood digestion and stress responses}

Once having the global analysis of proteomes, we considered of interest to make a more in-depth comparison of the four functional groups of proteins most likely involved in the process of blood digestion and in other processes related to blood feeding. Consequently, we selected the following functional groups: (i) proteins with peptidase activity, (ii) proteins involved in iron metabolism and transport, (iii) proteins involved in responses to oxidative stress and detoxification associated with blood feeding and, (iv) proteins involved in endocytosis, membrane traffic and protein transport (Table 2 and Fig. 1).

We identified 15 proteins with peptidase activity, 13 in unfed ticks and 9 in fed ticks, of which 7 were identified in both groups. These proteases belonged to four different groups (aspartic-type endopeptidase, cysteine-type endopetidase, metallopeptidase and serine-type endopeptidase), except two of them, in which the type of enzyme activity has still not been characterized (B4NAG0, B7PXW8). No predominance of one or another type of molecule was observed as a function of the physiological 
$\mathbf{A}$
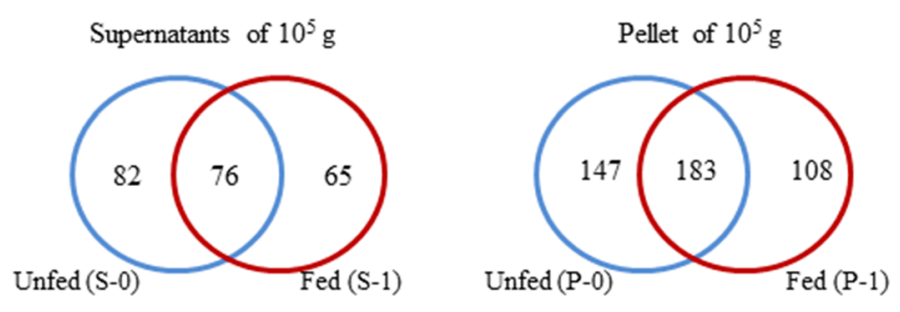

B

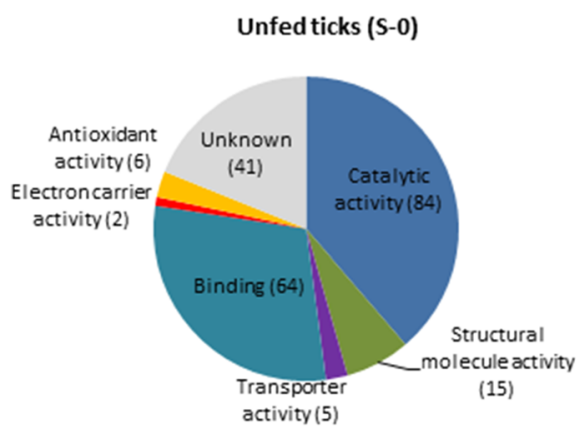

SOLUBLE FRACTIONS

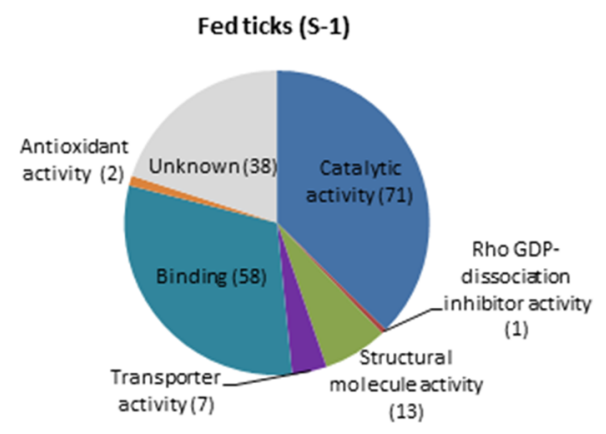

INSOLUBLE FRACTIONS

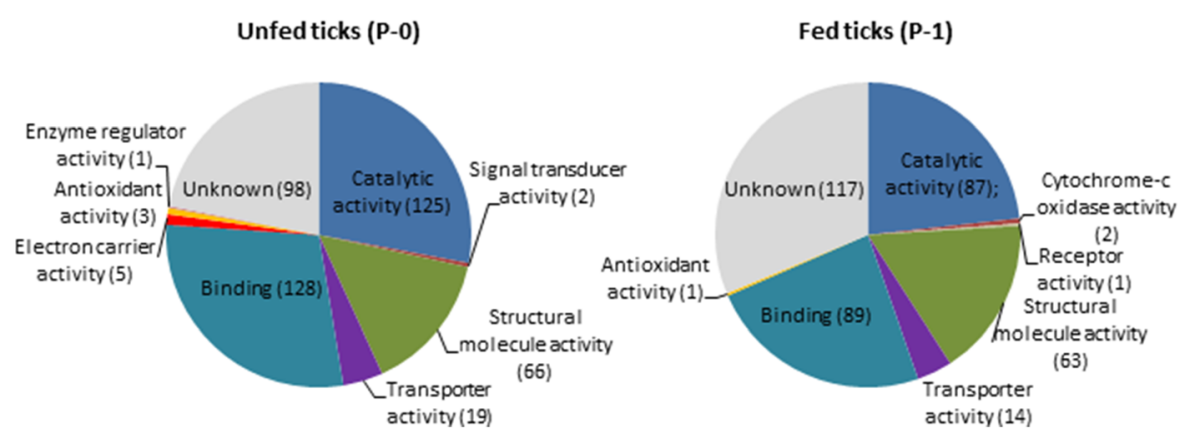

Fig. 3 Proteins identified in the fractions. a Number of proteins identified in each of the fractions obtained from the midgut of fed and unfed ticks. S-0, S-1, P-0 and P-1, soluble (S) and insoluble fractions (P) from midgut of unfed and fed ticks. b Classification according to their molecular function of the proteins identified in each of the fractions

conditions of the tissue analyzed and we only detected a lower abundance of the signal peptidase complex I protein in the fed ticks (1.28 emPAI in unfed versus 0.39 emPAI in fed).

Regarding the 13 proteins related to iron metabolism and transport, all of these were present in the midgut of unfed ticks and only 4 were also identified in fed ticks. These latter were aconitase, ATPase, cytochrome c oxidase and ferritin, without differences in the emPAI values between fed and unfed ticks (Table 2). The other proteins identified only in unfed specimens were the AAEL012552-PA (Q16LR5) protein and an uncharacterized protein (T1FN77), which shared 72-93\% identity with an NADH-ubiquinone oxidoreductase; cytochrome b- c1 complex; NADH dehydrogenase iron-sulphur protein; two NADH-ubiquinone reductases; a predicted protein (A7RKR4) and two uncharacterized proteins (Q86GF8, G6D2B9), which shared $82 \%$ and $84 \%$ identity with an aconitase hydratase.

We also have identified, mainly in fed ticks, 29 proteins involved in responses to oxidative stress and detoxification associated with blood feeding. As can be seen in Table 2, 15 were identified in the midgut of fed and unfed ticks, three only in unfed ticks and 11 only in fed ticks. According to the classification in the GO database, 11 of these proteins -chaperones of the T-complex protein 1, HSP70, HSP90, Gp96, the accessory gland protein, two peptidylpropyl isomerases, and endoplasmic reticulum glucose 
A

Unfed Fed

(Total tick proteins 414) (Total tick proteins 376)

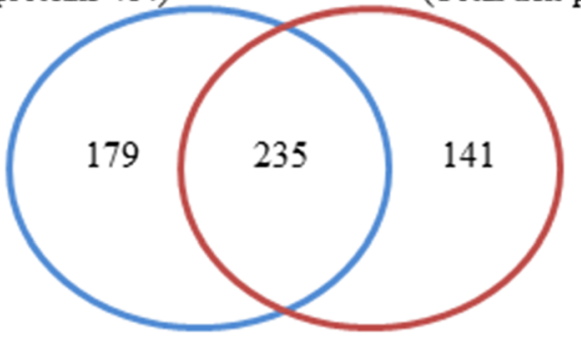

B

Protein Class

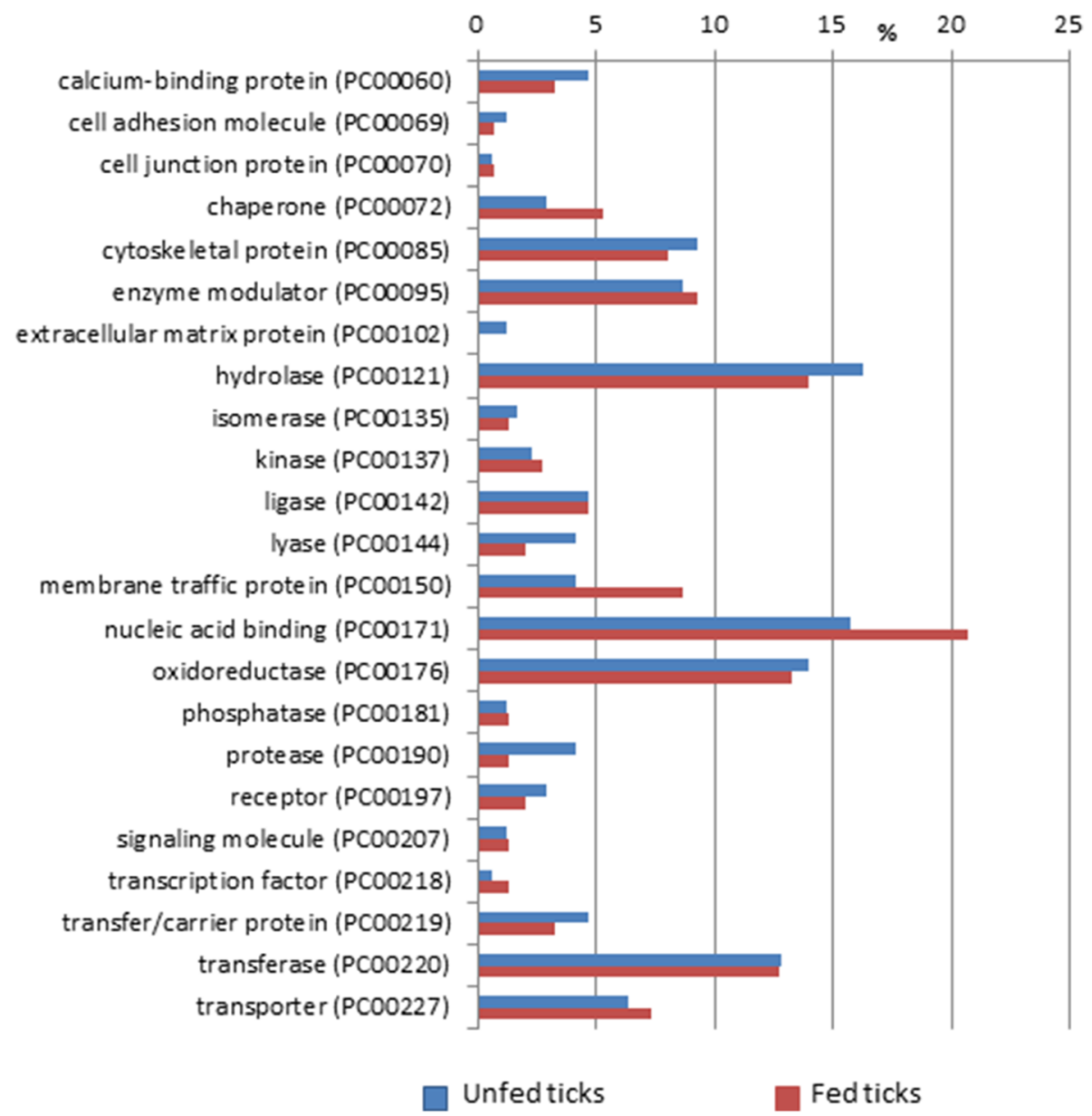

Fig. 4 Proteins identified in the midgut of unfed ticks and engorged ticks at $48 \mathrm{~h}$ post-feeding. a Number of proteins identified in each experimental group, fed and unfed ticks. $\mathbf{b}$ The proteins identified in the midgut of unfed and fed ticks were classified into protein classes using the Panther Classification System. Bars represent the percentage of proteins in each protein class relative to the total number of proteins in the group

regulated protein- could be involved in protein folding processes associated with stress responses. The other 18, among them glutathione peroxidase, thioredoxin peroxidase, superoxide dismutase, aldehyde dehydrogenase and others, could act as antioxidants in processes of detoxification and responses to oxidative stress.

Regarding intracellular blood digestion, it has been proposed that haemoglobin recognition and trafficking 


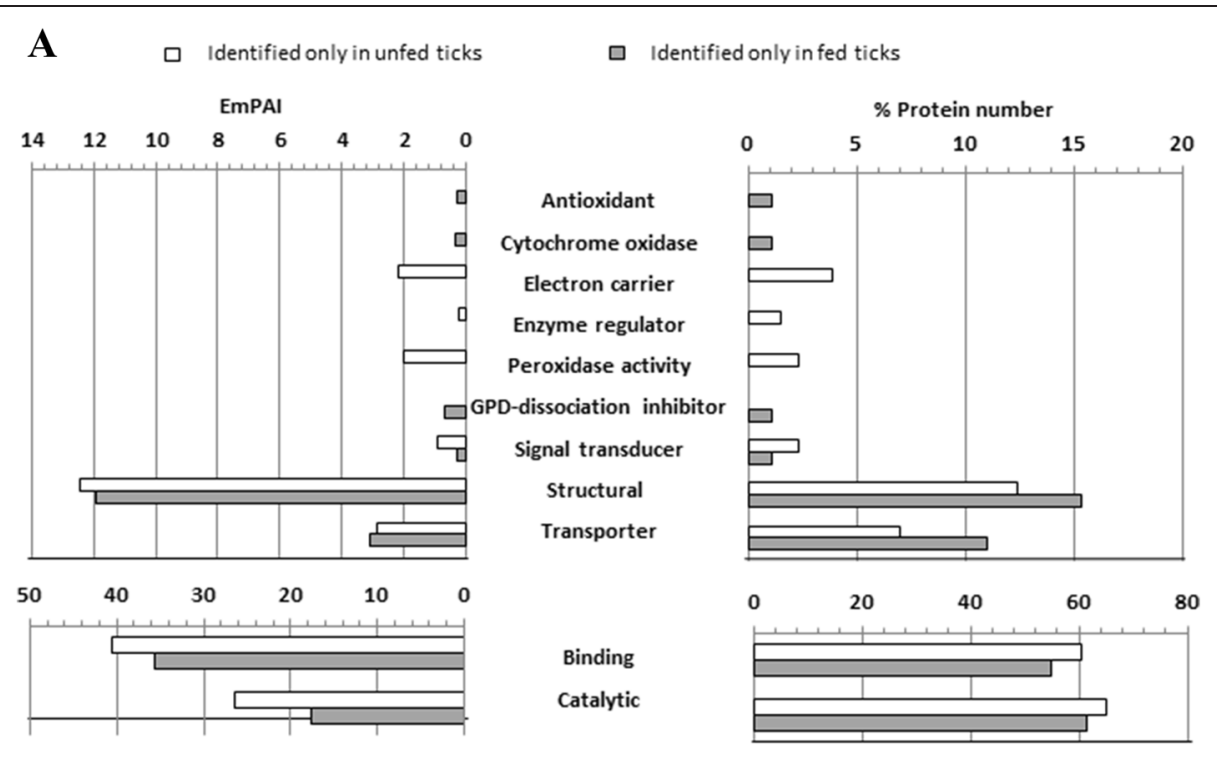

B Identified simultaneously in both, unfed and fed ticks

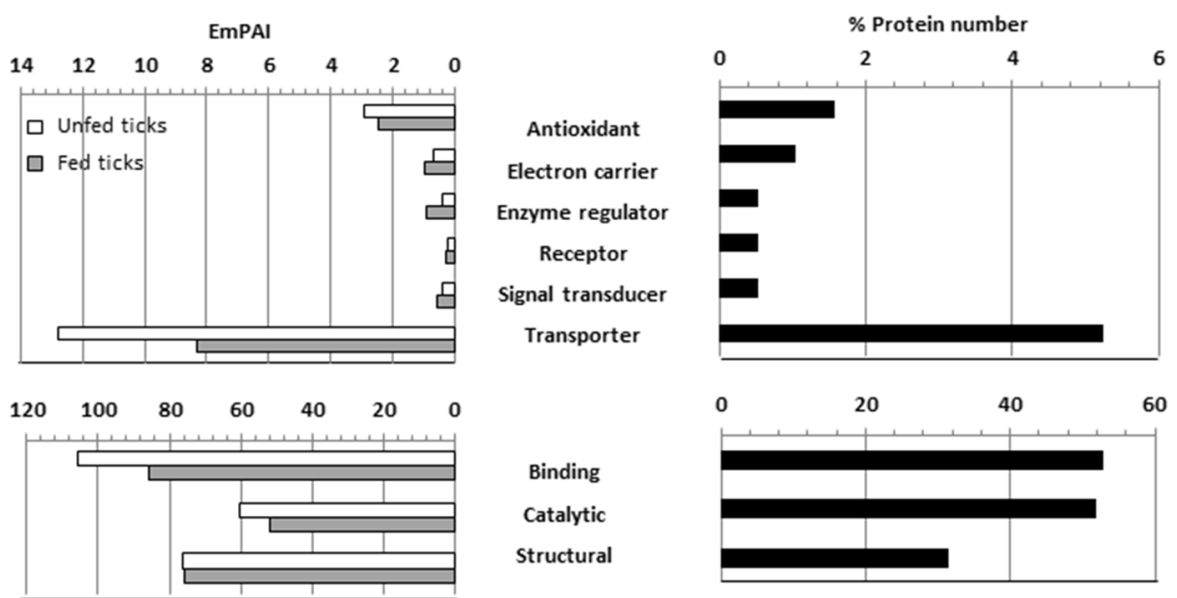

Fig. 5 Classification by molecular function of the proteins identified either only in unfed ticks or only in fed ticks (a) and simultaneously in both groups of ticks (b). \% Protein number is the ratio between the numbers of proteins identified in each category with respect to the total number of proteins classified. The emPAl value for each category was calculated as the sum of the emPAl of all the proteins in that category

within tick digestive cells utilizes molecular mechanisms analogous to the clathrin-dependent receptor-mediated endocytosis of mammalian cells [16]. Table 2 shows 15 proteins involved in endocytosis processes (clathrin, flotillin, AP-2 complex, endocytosis/signalling protein EHD1) intracellular protein transport (SEC61, cargo transport protein EMP24, glycoprotein 25I, transmembrane protein TMP21) and vesicle-mediated transport (cotoamer complex, alpha SNAP, vesicle-docking protein P115, synaptic vesicle-associated protein, vesicle coat complex COPII). Most of them (13 proteins) were found in the midgut of fed $O$. erraticus females, and six of them in both fed and unfed ticks. The latter showed similar emPAI values in both physiological states, suggesting that their expression level does not change after blood feeding.

\section{Discussion}

The midgut of ticks is a particularly promising target for the development of new control strategies. The luminal surface of the midgut can be accessed to by the host immune effectors and blood components ingested during blood feeding. Additionally, since blood meal digestion in ticks is intracellular, blood components may also enter midgut cells [22, 34]. Therefore, vaccine-induced antibodies and drugs present in host blood could reach their targets in the tick midgut after blood feeding. Proof of this is that the only two commercialized anti-tick vaccines available are based on an intestinal antigen $[35,36]$.

It has also been demonstrated that the ingestion of drugs present in blood may have a deleterious effect on ticks. An example of this is the effect of the recently 
Table 2 Proteins identified in the midgut from Ornitodoros erraticus females before feeding (unfed group) and after $48 \mathrm{~h}$ post-feeding (fed group) involved in the following biological activities and process: Peptidase activity, iron metabolism and transport, oxidoreductase, protein folding and response to stress and endocytosis, membrane traffic and protein

transport

\begin{tabular}{|c|c|c|c|c|c|c|c|c|c|}
\hline \multirow[t]{2}{*}{$\begin{array}{l}\text { Experimental } \\
\text { group }\end{array}$} & \multirow[t]{2}{*}{ Entry } & \multirow[t]{2}{*}{ Gene names } & \multirow[t]{2}{*}{ Protein names } & \multirow[t]{2}{*}{$\begin{array}{l}\text { Code in } \\
\text { Fig. } 1\end{array}$} & \multirow[t]{2}{*}{ Function (Gene Ontology) } & \multicolumn{2}{|c|}{$\begin{array}{l}\text { Num. of significant } \\
\text { sequences }\end{array}$} & \multicolumn{2}{|l|}{ emPAl } \\
\hline & & & & & & Unfed & Fed & Unfed & Fed \\
\hline \multicolumn{10}{|c|}{ Peptidase activity } \\
\hline Unfed, Fed & Q2WFX6 & AP & Aspartic protease & Pa1 & Aspartic-type endopeptidase & 2 & 2 & 0.32 & 0.32 \\
\hline Unfed, Fed & E7E820 & - & Cathepsin D2 & $\mathrm{Pa} 2$ & Aspartic-type endopeptidase & 2 & 3 & 0.34 & 0.26 \\
\hline Unfed, Fed & B7P6S9 & IscW_ISCW000202 & Tick legumain & Pa3 & Cysteine-type endopeptidase & 2 & 2 & 0.17 & 0.17 \\
\hline Unfed, Fed & F0J8F6 & - & Metallopeptidase (Fragment) & $\mathrm{Pa} 4$ & - & 2 & 3 & 0.22 & 0.41 \\
\hline Unfed, Fed & B7PA58 & IscW_ISCW003100 & Putative uncharacterized protein & Pa5 & Metalloexopeptidase & 2 & 2 & 0.14 & 0.14 \\
\hline Unfed, Fed & Q6U8A8 & - & Serine protease-like protein & Pa6 & Serine-type endopeptidase & 4 & 4 & 0.96 & 0.75 \\
\hline Unfed, Fed & Q09JL3 & - & Signal peptidase complexl & Pa7 & Serine-type peptidase & 5 & 2 & 1.28 & 0.39 \\
\hline Unfed & E2BXE8 & EAI_04817 & AFG3-like protein 2 & Pa8 & Metalloendopeptidase & 4 & - & 0.51 & - \\
\hline Unfed & B7Q203 & IscW_ISCW009180 & ATPase & Pa9 & Metalloendopeptidase & 3 & - & 0.26 & - \\
\hline Unfed & B7P573 & IscW_ISCW001592 & Processing peptidase beta subunit, & Pa10 & Metalloendopeptidase & 2 & - & 0.13 & - \\
\hline Unfed & B4NAG0 & Dwil\GK11711 & GK11711 & Pa11 & Peptidase activity & 2 & - & 0.36 & - \\
\hline Unfed & B7PXW8 & IscW_ISCW020703 & Signal peptidase complex, subunit SPC25 & Pa12 & Peptidase activity & 2 & - & 0.31 & - \\
\hline Fed & B7Q579 & IscW_ISCW021356 & Acylamino-acid-releasing enzyme & Pa13 & Serine-type peptidase & - & 2 & - & 0.08 \\
\hline Fed & M7CBK1 & UY3_00674 & Protein DDI1 like protein 2 & Pa14 & Aspartic-type endopeptidase & - & 2 & - & 0.06 \\
\hline Fed & & A0A087UYK2 & X975_16479 & Signal & $\begin{array}{l}\text { peptidase complex catalytic subunit } \\
\text { SEC } 11 C\end{array}$ & Pa15 & $\begin{array}{l}\text { Serine- } \\
\text { type }\end{array}$ & & \\
\hline peptidase & - & 2 & - & 0.21 & & & & & \\
\hline \multicolumn{10}{|c|}{ Iron metabolism and transport } \\
\hline Unfed, Fed & B9UNL8 & - & Aconitate/iron-regulatory protein & $\operatorname{lr} 1$ & 4 iron, 4 sulfur cluster binding & 2 & 3 & 0.3 & 0.1 \\
\hline Unfed, Fed & B7P592 & IscW_ISCW015613 & Amidophosphoribosyltransferase (ATase) & Ir2 & Iron-sulfur cluster binding & 2 & 3 & 0.24 & 0.19 \\
\hline Unfed, Fed & O99806 & - & Cytochrome c oxidase subunit 1 & Ir3 & Iron ion binding & 2 & 2 & 0.12 & 0.38 \\
\hline Unfed, Fed & A6N9Q6 & - & Ferritin & Ir4 & Iron ion transport & 2 & 2 & 0.36 & 0.36 \\
\hline Unfed & Q16LR5 & AAEL012552 & AAEL012552-PA & Ir5 & Iron-sulfur cluster binding & 3 & - & 0.13 & - \\
\hline Unfed & J3JUT5 & YQE_06758 & Cytochrome b-c1 complex subunit Rieske & Ir6 & 2 iron, 2 sulfur cluster binding & 2 & - & 0.24 & - \\
\hline Unfed & F4WQEO & G5I_08058 & NADH dehydrogenase [ubiquinone] iron-sulfur protein & Ir7 & 4 iron, 4 sulfur cluster binding & 2 & - & 0.2 & - \\
\hline Unfed & B7PNX4 & IscW_ISCW005985 & $\begin{array}{l}\text { NADH:ubiquinone oxidoreductase, NDUFV1/51 } \\
\text { kDa subunit, }\end{array}$ & Ir8 & 4 iron, 4 sulfur cluster binding & 2 & - & 0.13 & - \\
\hline Unfed & B7PBH7 & IscW_ISCW003299 & NADH-ubiquinone reductase & $\operatorname{lr} 9$ & Iron-sulfur cluster binding & 2 & - & 0.22 & - \\
\hline Unfed & A7RKR4 & v1g179073 & Predicted protein & $\operatorname{lr} 10$ & 4 iron, 4 sulfur cluster binding & 3 & - & 0.37 & - \\
\hline
\end{tabular}


Table 2 Proteins identified in the midgut from Ornitodoros erraticus females before feeding (unfed group) and after $48 \mathrm{~h}$ post-feeding (fed group) involved in the following biological activities and process: Peptidase activity, iron metabolism and transport, oxidoreductase, protein folding and response to stress and endocytosis, membrane traffic and protein transport (Continued)

\begin{tabular}{|c|c|c|c|c|c|c|c|c|c|}
\hline Unfed & Q86GF8 & - & Putative uncharacterized protein & $\operatorname{lr} 11$ & 4 iron, 4 sulfur cluster binding & 2 & - & 0.08 & - \\
\hline Unfed & G6D2B9 & KGM_16016 & Uncharacterized protein & $\operatorname{lr} 12$ & 4 iron, 4 sulfur cluster binding & 3 & - & 0.38 & - \\
\hline Unfed & T1FN77 & HELRODRAFT_185731 & Uncharacterized protein & $\operatorname{lr} 13$ & Iron-sulfur cluster binding & 3 & - & 0.13 & - \\
\hline \multicolumn{10}{|c|}{ Oxidoreductase, protein folding and response to stress } \\
\hline Unfed, Fed & A1KXI6 & - & Blo $t$ aldehyde dehydrogenase allergen & Ox1 & Oxidoreductase & 2 & 3 & 0.44 & 0.49 \\
\hline Unfed, Fed & B7P4E1 & IscW_ISCW000393 & Glutamate dehydrogenase & $0 \times 2$ & Oxidoreductase & 3 & 3 & 0.17 & 0.28 \\
\hline Unfed, Fed & B7QKE4 & IscW_ISCW023707 & Glycerol-3-phosphate dehydrogenase & Ox3 & Oxidoreductase & 2 & 2 & 0.08 & 0.18 \\
\hline Unfed, Fed & Q4PLZO & - & Mitochondrial malate dehydrogenase & Ox4 & Oxidoreductase & 2 & 6 & 0.35 & 1.83 \\
\hline Unfed, Fed & Q09JE3 & - & Superoxide dismutase [Cu-Zn] & Ox5 & Oxidoreductase & 3 & 3 & 1.87 & 1.36 \\
\hline Unfed, Fed & A6N9S1 & - & Thioredoxin peroxidase & Ox6 & Oxidoreductase & 6 & 3 & 1.92 & 0.54 \\
\hline Unfed, Fed & A6NA14 & - & Truncated peroxiredoxin & Ox7 & Oxidoreductase & 3 & 3 & 0.55 & 0.55 \\
\hline Unfed, Fed & F0J8S6 & - & FKBP-type peptidyl-prolyl cis-trans isomerase & Ox8 & Protein folding & 3 & 2 & 0.35 & 0.26 \\
\hline Unfed, Fed & B2ZWT4 & CyPA & Peptidyl-prolyl cis-trans isomerase & Ox9 & Protein folding & 3 & 3 & 0.84 & 0.84 \\
\hline Unfed, Fed & & A0A087UTZ9 & X975_09861 & $\mathrm{T}-$ & complex protein 1 subunit alpha & $0 \times 10$ & $\begin{array}{l}\text { Protein } \\
\text { folding }\end{array}$ & 2 & 3 \\
\hline 0.11 & 0.4 & & & & & & & & \\
\hline Unfed, Fed & E9GYM5 & DAPPUDRAFT_306806 & T-complex protein 1 subunit gamma & Ox11 & Protein folding & 3 & 3 & 0.17 & 0.33 \\
\hline Unfed, Fed & F0J8P3 & - & HSP70 family member & $0 \times 12$ & Protein folding/response to stress & 12 & 11 & 4.0 & 3.5 \\
\hline Unfed, Fed & B7QI01 & IscW_ISCW014265 & Hsp90 protein & $0 \times 13$ & Protein folding/response to stress & 16 & 21 & 1.17 & 3.03 \\
\hline Unfed, Fed & B7QC85 & IscW_ISCW022766 & Tumor rejection antigen (Gp96), & Ox14 & Protein folding/response to stress & 5 & 9 & 0.95 & 1.46 \\
\hline Unfed, Fed & Q2YFF0 & - & Glutathione transferase mu class & Ox15 & Response to stress and detoxification & 2 & 2 & 0.27 & 0.25 \\
\hline Unfed & B7POP1 & IscW_ISCW016225 & DNA topoisomerase 2 & Ox16 & Oxidoreductase & 2 & - & 0.38 & - \\
\hline Unfed & B7QBE5 & IscW_ISCW013475 & Lipophorin receptor & Ox17 & Oxidoreductase & 2 & - & 0.27 & - \\
\hline Unfed & Q2XW18 & PHGPX & Glutathione peroxidase & Ox18 & Response to oxidative stress & 4 & - & 1.12 & - \\
\hline Fed & & A0A087U1A2 & X975_14796 & Copper & chaperone for superoxide dismutase & Ox19 & & & \\
\hline $\begin{array}{l}\text { Oxidation- } \\
\text { reduction } \\
\text { process }\end{array}$ & - & 2 & - & 0.24 & & & & & \\
\hline Fed & Q6DJQ3 & aldh9a1 TEgg018109.1-001 & Aldehyde dehydrogenase 9 family, member A1 & $0 \times 20$ & Oxidoreductase & - & 2 & - & 0.12 \\
\hline Fed & B7Q8W6 & IscW_ISCW010532 & Alkyl hydroperoxide reductase, thiol specific antioxidant & Ox21 & Oxidoreductase & - & 2 & - & 0.27 \\
\hline Fed & U6PA25 & HCOI_01121300 & Endonuclease exonuclease phosphatase & $0 \times 22$ & Oxidoreductase & - & 2 & - & 0.07 \\
\hline Fed & I1WDI0 & - & Putative 17 beta-hydroxysteroid dehydrogenase & $0 \times 23$ & Oxidoreductase & - & 2 & - & 0.34 \\
\hline Fed & E9HGSO & DAPPUDRAFT_228809 & Uncharacterized protein & $0 \times 24$ & Oxidoreductase & - & 2 & - & 0.22 \\
\hline
\end{tabular}


Table 2 Proteins identified in the midgut from Ornitodoros erraticus females before feeding (unfed group) and after $48 \mathrm{~h}$ post-feeding (fed group) involved in the following biological activities and process: Peptidase activity, iron metabolism and transport, oxidoreductase, protein folding and response to stress and endocytosis, membrane traffic and protein transport (Continued)

\begin{tabular}{|c|c|c|c|c|c|c|c|c|c|}
\hline Fed & T1FVK5 & HELRODRAFT_194011 & Uncharacterized protein & Ox25 & Oxidoreductase & - & 2 & - & 0.12 \\
\hline Fed & B7QJ21 & IscW_ISCW023397 & Chaperonin complex component, TCP-1 eta subunit, & $0 \times 26$ & Protein folding & - & 2 & - & 0.21 \\
\hline Fed & Q0ZBX3 & AG-0383 F-Gp & Putative accessory gland protein & $0 \times 27$ & Protein folding & - & 2 & - & 0.24 \\
\hline Fed & & A0A067RDC2 & L798_09307 & T- & complex protein 1 subunit delta & $0 \times 28$ & $\begin{array}{l}\text { Protein } \\
\text { folding }\end{array}$ & - & 2 \\
\hline- & 0.37 & & & & & & & & \\
\hline Fed & F0J987 & - & Endoplasmic reticulum glucose-regulated protein & Ox29 & Protein folding/response to stress & - & 4 & - & 0.67 \\
\hline \multicolumn{10}{|c|}{ Endocytosis, membrane traffic and protein transport } \\
\hline Unfed, Fed & B7QHSO & IscW_ISCW015012 & Flotillin & Et1 & - & 4 & 2 & 0.33 & 0.14 \\
\hline Unfed, Fed & B7P427 & IscW_ISCW001550 & Transmembrane protein Tmp21 & Et2 & Protein transport & 2 & 2 & 0.48 & 0.30 \\
\hline Unfed, Fed & В7Р6Р0 & IscW_ISCW001001 & Glycoprotein 25 I & Et3 & Protein transport & 3 & 3 & 0.63 & 0.44 \\
\hline Unfed, Fed & B7PUK8 & IscW_ISCW019441 & Clathrin heavy chain & Et4 & Vesicle-mediated transport & 12 & 10 & 0.25 & 0.21 \\
\hline Unfed, Fed & BTPQEO & IscW_ISCW006283 & Coatomer, alpha chain & Et5 & Vesicle-mediated transport & 2 & 2 & 0.06 & 0.06 \\
\hline Unfed, Fed & B7PDY5 & IscW_ISCW004922 & Vesicle coat complex COPII, GTPase subunit SAR1 & Et6 & Vesicle-mediated transport & 3 & 3 & 0.53 & 0.60 \\
\hline Unfed & B7Q4N0 & IscW_ISCW011849 & Cargo transport protein EMP24 & Et7 & Protein transport & 2 & - & 0.22 & - \\
\hline Unfed & B7PGX4 & IscW_ISCW003940 & Synaptic vesicle-associated integral membrane protein & Et8 & Vesicle-mediated transport & 4 & - & 0.65 & - \\
\hline Fed & B7QNW0 & IscW_ISCW015531 & $\begin{array}{l}\text { Protein required for fusion of vesicles in vesicular transport, } \\
\text { alpha-SNAP }\end{array}$ & Et9 & Protein transport & - & 3 & - & 0.35 \\
\hline Fed & B7PYR6 & IscW_ISCW020077 & Protein transport protein SEC61 alpha subunit & Et10 & Protein transport & - & 4 & - & 0.32 \\
\hline Fed & B7P806 & IscW_ISCW016976 & Vesicle docking protein P115 & Et11 & Protein transport & - & 2 & - & 0.08 \\
\hline Fed & B7Q6V9 & IscW_ISCW011108 & AP-2 complex subunit beta-1 & Et12 & Vesicle-mediated transport & - & 5 & - & 0.17 \\
\hline Fed & B7QAA7 & IscW_ISCW012850 & Coatomer beta subunit & Et13 & Vesicle-mediated transport & - & 3 & - & 0.12 \\
\hline Fed & $\mathrm{B} 7 \mathrm{QCH} 5$ & IscW_ISCW022475 & Coatomer gamma subunit & Et14 & Vesicle-mediated transport & - & 3 & - & 0.14 \\
\hline Fed & B7Q5G4 & IscW_ISCW021581 & Endocytosis/signaling protein EHD1 & Et15 & Vesicle-mediated transport & - & 2 & - & 0.18 \\
\hline
\end{tabular}


commercialized drug Fluralaner (Bravecto ${ }^{\mathrm{Tx}}$ ), although it does not target intestinal proteins, its oral administration has proved to be effective against several tick species, causing their death a few hours after feeding [37-39].

In light of the above, it is clear that the knowledge of the gut proteome and changes in protein expression upon feeding and digestion provides key information for identifying and selecting new targets for the development of alternative control strategies. Accordingly, the aim of the present work was to construct the intestinal proteome at two moments in the trophogonic cycle of the tick, namely, unfed and at $48 \mathrm{~h}$ post-feeding. These sampling time-points were selected considering the phases of digestion in argasids, in order to analyze midgut tissues under basal conditions and during the process of digestion. In argasids, digestion begins as soon as they detach themselves from the host and, as has been described in O. moubata, it comprises three phases whose duration depends on environmental and physiological factors [17, 18]. During the first hours post-feeding, blood begins to become concentrated, excess water and sodium ions being expelled through the coxal glands; then, erythrocyte haemolysis begins, and the digestion of haemoglobin is insignificant. The second stage ( $2-5$ days) is the phase of intensive digestion, with uptake of the blood meal components into enterocytes, their digestion, and the elimination of residues. The third phase may be a long period of very slow digestion, enabling the tick to fast for long periods of time [17, 18]. Moreover, in O. erraticus we had previously observed that the expression of particular intestinal antigens, even though they are expressed constitutively along the trogophonic cycle, increases significantly after a blood meal, with a maximum at 24-72 h post-detachment [11].

In the present work the protocol used for sample collection and pre-processing for mass spectrometry analysis involved sample fractionation by centrifugation followed by separation of the proteins in each fraction by SDS-PAGE. Bearing in mind that in ticks collected after feeding on a host the major constraint for the successful identification of tick proteins is a large amount of host protein [40], we sliced the gel into pieces and analysed each gel piece individually. In this way, the very abundant host proteins, such as haemoglobin and albumin, were concentrated in a few gel pieces, thus preventing these proteins from masking the detection of most tick proteins in the remaining gel pieces. Proof of this is the fact that the numbers of non-redundant tick proteins identified in the midgut of the fed and unfed females were similar: 376 and 414 respectively.

Overall, the proteomic analyses of the midgut of unfed and fed ticks identified 555 non-redundant tick proteins. The analysis of Molecular Function gene ontology showed a significant proportion of proteins with an unknown function in all fractions from both groups (Fig. 3b). This was to a certain extent expected because $O$. erraticus is a non-model species and its genome is basically unknown. Apart from the proteins with unknown function, those most represented in all fractions were proteins with catalytic and binding activity (Fig. 3b), consistent with their role in the intracellular processing of the blood meal [21]. A notably high proportion of structural proteins was identified in both unfed and fed ticks, mainly in the P-0 and P-1 insoluble fractions, most of these proteins being structural constituents of ribosomes, such as ribosomal RNA 40S, 60S, and other ribosomal genes involved in protein synthesis [21, 41]. Moreover, it was also suggested that ribosomes would serve as hub for translational folding, chaperone interaction, degradation, and stress response [42].

Comparison of the midgut proteomes of unfed and fed ticks did not reveal any great differences in either the number or the type of proteins identified, as may be inferred from the classifications based on Molecular Function and Protein class (Figs. 4 and 5). These results were not unexpected since in similar studies performed in ixodid ticks it was observed that the composition of the midgut proteome is highly stable during the early phase of feeding [25, 41]. By contrast, at transcriptome level important changes in gene expression are seen in response to tick feeding; in particular, most of the proteins involved in blood digestion are upregulated. According to other authors, this suggests that post-transcriptional and post-translational regulation mechanisms can likely make proteome and transcriptome dynamics to have different kinetics, avoiding a direct correlation between mRNA and protein level [21, 24, 25, 41].

However, after a more detailed analysis of certain groups of proteins identified in O. erraticus putatively involved directly in blood meal digestion -including protein digestion (peptidase activity), iron metabolism, enzymes involved in oxidative stress and detoxification and membrane traffic and transport- we detected some differences between the fed and unfed ticks. It should be noted that some of the differences observed in protein composition could in fact represent quantitative differences in the expression level of the proteins, since the least abundant proteins would be below the threshold of detection by MS.

The pathway of haemoglobin degradation in ixodids proceeds via the generation of large initial fragments $(8-11 \mathrm{kDa})$ to smaller haemoglobin-derived peptides $(2-7 \mathrm{kDa})$, which are finally hydrolysed to dipeptides and free amino acids [16]. The degradation pathway is initiated by endopeptidases of the aspartic and cysteine classes (cathepsin D supported by cathepsin L and legumain), after which a cathepsin B participates in the production of smaller fragments, and finally the pool of 
peptide fragments is degraded into dipeptides and amino acids through the action of cathepsin C, cathep$\sin \mathrm{B}$, a carboxipeptidase and a leucine aminopeptidase $[16,43]$. In argasids, information about the machinery of blood digestion is very scant and limited to a previous description of protease activity in the midgut of $O$. tolozani [44] and to the more recent identification of two cystatins in O. moubata [29]. In O. erraticus we have identified 15 proteins with peptidase activity, one of which is a cathepsin D2 and a legumain. We also identified several proteins with metalloprotease activity, some of which could exert functions similar to that of leucine aminopeptidase, since they belong to the same enzyme class (metallopeptidase class) [16, 45]. All of these proteins could be responsible for the cleavage of the haemoglobin molecule in spite of other important function like midgut cellular integrity/remodelling and embryogenesis $[43,46]$.

During blood digestion, ticks are exposed to an enormous amount of free iron, which must be appropriately used and detoxified. Whereas iron is an essential component of several proteins involved in fundamental biochemical activities and an essential nutrient for reproduction and embryonic development, it is also potentially toxic owing to its ability to generate reactive oxygen species [47]. For this reason, iron homeostasis must be tightly regulated by an orchestrated set of proteins that govern iron uptake, utilization, transport and storage [48]. Here we have identified 13 proteins classified as iron-binding proteins in the gene ontology database. All of them were expressed in the intestine of unfed females and only four also in fed females. This suggests a putative decreased expression of this protein group during blood feeding, an effect also observed by Anderson et al. [21] in the intestinal transcriptome of Dermacentor variabilis. In hard ticks it has been demonstrated that iron-regulatory proteins and ferritin play important roles in iron metabolism. Ironregulatory proteins mediate the translational control of ferritin in response to iron levels [47]. Ferritins are crucial antioxidant molecules that protect hard ticks from ironmediated oxidative stress during blood feeding, and have shown promising results as vaccine antigens against tick infestation [47-51]. In the O. erraticus females we found an aconitase/iron-regulatory protein and a homologue of the $O$. parkeri ferritin, whose expression in the midgut did not change after a blood meal. A similar result has been reported for Haemaphysalis longicornis ferritins [52].

We also identified several chaperones and antioxidant proteins with oxidoreductase activity, probably involved in stress responses and detoxification reactions associated with blood feeding. In this group, we identified 29 proteins, most of which were found in fed ticks; this could indicate, as in the case of the mialome of Dermacentor marginatus [21], that the expression of this protein group increases during blood feeding. We have identified several antioxidant enzymes such as GSTs, thioredoxins, glutathione peroxidase and superoxide dismutase (SOD) which have already been identified in the midgut of several ixodid species, where they are known to play an important role in cellular stress responses such as those occurring as a result of blood feeding as well as in innate immunity [21, 23, 53, 54]. Interestingly SOD, which functions as an antioxidant by scavenging free radicals, appears to bind haeme. This suggests that in addition to its antioxidant properties it could function in haeme trafficking, which would be important in the intracellular tick blood meal digestion process $[21,55]$.

Regarding the intracellular blood digestion, it is proposed that haemoglobin recognition and trafficking in digestive cells utilize molecular mechanisms analogous to the clathrin-dependent receptor-mediated endocytosis of mammalian cells [16]. In O. erraticus we found 15 proteins (most of them in fed midguts) that may play some role in directing macromolecules into midgut cells and in intracellular protein transport. Clathrin and coatomer proteins are required to coat vesicles that are important for cargo selection and the direction of transfer [56]. The AP-2 complex belonging to the adaptin family, also identified in the midgut of Rhipicephalus microplus, mediates endocytosis by the plasma membrane and is part of the vesicle coat [23, 57]. TMP21 and related proteins, such as glycoprotein 251 and the cargo transport protein EMP24, are major membrane components of COPI- and COPII-coated vesicles and are involved in the endoplasmic reticulum to Golgi transport $[58,59]$. Flotillins have been implicated in numerous processes, including endocytosis, signal transduction and regulation of the cortical cytoskeleton. However, the molecular mechanisms that underlie flotillin function in these different cases are still poorly understood [60]. According to Kongsuwan et al. [23] the evidence suggests that the transport machineries in tick midguts are complex and tightly regulated and the major challenge now is to understand the roles of these proteins in tick gut function.

\section{Conclusions}

In this study we report for the first time the collection and analysis of the midgut proteome of an argasid tick species. This analysis includes a comparison of proteomic changes in response to tick feeding and blood digestion, providing hitherto unknown molecular information about the machinery of argasids for blood digestion. Analysis of the corresponding transcriptomes will likely increase and complement this information, allowing a more in-depth understanding of the biochemistry and physiology of blood digestion. This information could be a starting point for the identification and selection of new targets for the development of alternative control strategies. 


\section{Additional files}

Additional file 1: Table S1. Non-redundant tick proteins identified in the midgut of unfed ticks. (XLSX $78 \mathrm{~kb}$ )

Additional file 2: Table S2. Non-redundant tick proteins identified in the midgut of engorged ticks at $48 \mathrm{~h}$ post-feeding (fed group). (XLSX $115 \mathrm{~kb}$ )

Additional file 3: Table S3. Non-redundant host proteins identified in Soluble fraction, S-1, from midgut of engorged ticks at $48 \mathrm{~h}$ post-feeding (fed group). (XLSX $45 \mathrm{~kb}$ )

Additional file 4: Figure S1. Pie charts showing the amino acid coverage for all the identified protein with two unique significant peptides in the different midgut fractions. The identified proteins in each fraction after mining either the BCBInr_metozoa or the EST_acari databases are included. For each chart, the proteins are grouped according to the sequence coverage into the following ranges: < $10 \%, 10-25 \%, 25-40 \%$, $40-60 \%$ and $>60 \%$. For each sequence coverage range, the percentage of grouped proteins is given. (TIFF $104 \mathrm{~kb}$ )

Additional file 5: Table S4. Non-redundant proteins identified only in unfed ticks, classified by their molecular function using the UniProt tools. (XLSX $88 \mathrm{~kb})$

\section{Competing interests}

The authors declare that they have no competing interests.

\section{Authors' contributions}

AO, RPS conceived the study and designed the experiments. POM maintained the tick colony and prepared the midgut protein extracts. AO, RPS, RMR and POM collaborated in the data analysis. AO, RPS, RMR collaborated in writing and editing the manuscript. All authors read and approved the final version of the manuscript.

\section{Authors' information}

All authors come from the Instituto de Recursos Naturales y Agrobiología (IRNASA, CSIC), Parasitology Laboratory. Salamanca, Spain.

\section{Acknowledgments}

The authors are grateful to Rocío Vizcaíno Marín and María González Sánchez, from the Instituto de Recursos Naturales y Agrobiología de Salamanca (IRNASA, CSIC) (Spain), for their skilful technical assistance, and to Dr. Luz Valero, from the Proteomics Unit of the University of Valencia (Spain), for her assistance in the MS analyses. We acknowledge support of the publication fee by the CSIC Open Access Publication Support Initiative through its Unit of Information Resources for Research (URICI). This research was funded by project AGL2013-42745-P granted by the Spanish Ministry of Economy and Competitiveness.

Received: 5 August 2015 Accepted: 7 October 2015

Published online: 12 October 2015

\section{References}

1. de la Fuente J, Estrada-Peña A, Venzal JM, Kocan KM, Sonenshine DE. Overview: ticks as vectors of pathogens that cause disease in humans and animals. Front Biosci. 2008;13:6938-46.

2. Manzano-Román R, Díaz-Martín V, de la Fuente J, Pérez-Sánchez R. Soft ticks as pathogen vectors: distribution, surveillance and control. In: Manjur S, editor. Parasitology. Rijeka, Croatia.: Intech; 2012. p. 125-62.

3. Cutler SJ. Relapsing fever-a forgotten disease revealed. J Appl Microbiol. 2010;108:1115-22.

4. Sánchez-Vizcaíno JM, Mur L, Gomez-Villamandos JC, Carrasco L. An update on the epidemiology and pathology of African swine fever. J Comp Path. 2015;152:9e21

5. Díaz-Martín V, Manzano-Román R, Obolo-Mvoulouga P, Oleaga A, PérezSánchez R. Development of vaccines against ornithodoros soft ticks: an update. Ticks Tick Borne Dis. 2015;6:211-20.

6. Astigarraga A, Oleaga-Pérez A, Pérez-Sánchez R, Encinas-Grandes A. A study of the vaccinal value of various extracts of concealed antigens and salivary gland extracts against Ornithodoros erraticus and Ornithodoros moubata. Vet Parasitol. 1994:60:133-47.
7. George JE, Pound JM, Davey RB. Chemical control of ticks on cattle and the resistance of these parasites to acaricides. Parasitology. 2004;129(Suppl):S353-66.

8. Ghosh S, Azhahianambi P, Yadav MP. Upcoming and future strategies of tick control: a review. J Vector Borne Dis. 2007:44:79-89.

9. Guerrero FD, Miller RJ, de Pérez León AA. Cattle tick vaccines: many candidate antigens, but will a commercially viable product emerge? Int J Parasitol. 2012:42:421-7.

10. Manzano-Román R, Encinas-Grandes A, Pérez-Sánchez R. Antigens from the midgut membranes of Ornithodoros erraticus induce lethal anti-tick immune responses in pigs and mice. Vet Parasitol. 2006;135:65-79.

11. Manzano-Román R, García-Varas S, Encinas-Grandes A, Pérez-Sánchez R. Purification and characterization of a $45-\mathrm{kDa}$ concealed antigen from the midgut membranes of Ornithodoros erraticus that induces lethal anti-tick immune responses in pigs. Vet Parasitol. 2007;145:314-25.

12. Willadsen P. Anti-tick vaccines. Parasitology. 2004;129:S367-87.

13. Popara M, Villar M, Mateos-Hernández L, de Mera IGF, Marina A, del Valle M, et al. Lesser protein degradation machinery correlates with higher BM86 tick vaccine efficacy in Rhipicephalus annulatus when compared to Rhipicephalus microplus. Vaccine. 2013;31:4728-35.

14. Maritz-Olivier C, van Zyl W, Stutzer C. A systematic, functional genomics, and reverse vaccinology approach to the identification of vaccine candidates in the cattle tick Rhipicephalus microplus. Ticks Tick Borne Dis. 2012;3:179-87.

15. Kocan KM, de la Fuente J, Blouin EF, Garcia-Garcia JC. Anaplasma marginale (Rickettsiales: Anaplasmataceae): recent advances in defining host-pathogen adaptations of a tick-borne rickettsia. Parasitology. 2004;129:285-300.

16. Sojka D, Franta Z, Horn M, Caffrey CR, Mareš M, Kopáček P. New insights into the machinery of blood digestion by ticks. Trends Parasitol. 2013:29:276-85.

17. Akov S. Blood digestión in ticks. In: Oberchain, FD and Gallun, R, editors. Physiology of ticks. Oxford, England: Pergamon Press Ltd.; 1982:197-212

18. Coons LB, Rosell-Davis R, Tarnowski B. Bloodmeal digestion in ticks. In: Sauer $J$ R, Hair JA, editors. Morphology, physiology, and behavioral biology of ticks. Chichester, England: Ellis Horwood limited; 1986:248-73

19. Mans BJ, Neitz AW. Adaptation of ticks to a blood-feeding environment: evolution from a functional perspective. Insect Biochem Mol Biol. 2004;34:1-17.

20. Caperucci D, Bechara GH, Camargo Mathias MI. Ultrastructure features of the midgut of the female adult Amblyomma cajennense ticks Fabricius, 1787 (Acari: Ixodidae) in several feeding stages and subjected to three infestations. Micron. 2010:41:710-21.

21. Anderson JM, Sonenshine DE, Valenzuela JG. Exploring the mialome of ticks: an annotated catalogue of midgut transcripts from the hard tick, Dermacentor variabilis (Acari: Ixodidae). BMC Genomics. 2008;9:552.

22. Rachinsky A, Guerrero FD, Scoles GA. Proteomic profiling of Rhipicephalus (Boophilus) microplus midgut responses to infection with Babesia bovis. Vet Parasitol. 2008;152:294-313.

23. Kongsuwan K, Josh P, Zhu Y, Pearson R, Gough J, Colgrave ML. Exploring the midgut proteome of partially fed female cattle tick (Rhipicephalus (Boophilus) microplus). J Insect Physiol. 2010:56:212-26.

24. Heekin AM, Guerrero FD, Bendele KG, Saldivar L, Scoles GA, Dowd SE, et al. Gut transcriptome of replete adult female cattle ticks, Rhipicephalus (Boophilus) microplus, feeding upon a Babesia bovis-infected bovine host. Parasitol Res. 2013;112:3075-90.

25. Schwarz A, Tenzer S, Hackenberg M, Erhart J, Gerhold-Ay A, Mazur J, et al. A systems level analysis reveals transcriptomic and proteomic complexity in Ixodes ricinus midgut and salivary glands during early attachment and feeding. Mol Cell Proteomics. 2014;13:2725-35.

26. Kotsyfakis M, Schwarz A, Erhart J, Ribeiro JM. Tissue- and time-dependent transcription in Ixodes ricinus salivary glands and midguts when blood feeding on the vertebrate host. Sci Rep. 2015:5:9103.

27. Grandjean O. Blood digestion in Ornithodoros moubata Murray sensu strictu Walton females (Ixodoidea: Argasidae) II. Modification of midgut cells related to digestive cycle and triggering action of mating. Ann Parasitol Hum Comp. 1983:58:493-14.

28. Grandjean O. Blood digestion in Ornithodoros moubata Murray sensu strictu Walton females (Ixodoidea: Argasidae). I. Biochemical changes in midgut cells related to intracellular digestion. Acarologia. 1984;25:147-65.

29. Grunclová L, Horn M, Vancová M, Sojka D, Franta Z, Mares M, et al. Two secreted cystatins of the soft tick Ornithodoros moubata: differential expression pattern and inhibitory specificity. Biol Chem. 2006:387:1635-44. 
30. Laemmli UK. Cleavage of structural proteins during the assembly of the head of bacteriophage T4. Nature. 1970;227:680-5.

31. Rappsilber J, Ryder U, Lamond Al, Mann M. Large scale proteomic analysis of the human spliceosome. Genome Res. 2002;12:1231-45.

32. Ishihama Y, Oda Y, Tabata T, Sato T, Nagasu T, Rappsilber J, et al. Exponentially modified protein abundance index (emPAl) for estimation of absolute protein amount in proteomics by the number of sequenced peptides per protein. Mol Cell Proteomics. 2005;4:1265-72.

33. Mi H, Muruganujan A, Thomas PD. PANTHER in 2013: modeling the evolution of gene function, and other gene attributes, in the context of phylogenetic trees. Nucleic Acids Res. 2013;41(Database issue):D377-86.

34. Jeffers LA, Michael R. The movement of proteins across the insect and tick digestive system. J Insect Physiol. 2008;54:319-32.

35. Willadsen P, Bird P, Cobon GS, Hungerford J. Commercialisation of a recombinant vaccine against Boophilus microplus. Parasitology. 1995; 110:S43-50

36. Canales M, Enriquez A, Ramos E, Cabrera D, Dandie H, Soto A, et al. Large-scale production in Pichia pastoris of the recombinant vaccine Gavac against cattle tick. Vaccine. 1997;15:414-22.

37. Fisara P, Webster M. A randomized controlled trial of the efficacy of orally administered fluralaner (Bravecto ${ }^{\mathrm{TM}}$ ) against induced Ixodes holocyclus (Australian paralysis tick) infestations on dogs. Parasit Vectors. 2015;8:257.

38. Taenzler J, Liebenberg J, Roepke RK, Heckeroth AR. Prevention of transmission of Babesia canis by Dermacentor reticulatus ticks to dogs treated orally with fluralaner chewable tablets $\left(\right.$ Bravecto $\left.^{\mathrm{TM}}\right)$. Parasit Vectors. 2015;8:305.

39. Williams H, Zoller H, Roepke RK, Zschiesche E, Heckeroth AR. Fluralaner activity against life stages of ticks using Rhipicephalus sanguineus and Ornithodoros moubata IN in vitro contact and feeding assays. Parasit Vectors. 2015:8:90.

40. Popara M, Villar M, de la Fuente J. Proteomics characterization of tick-hostpathogen interactions. Methods Mol Biol. 2015;1247:513-27.

41. Villar M, Popara M, Ayllón N, de Mera IG F, Mateos-Hernández L, Galindo RC, et al. A systems biology approach to the characterization of stress response in Dermacentor reticulatus tick unfed larvae. PLOS ONE. 2014;9, e89564.

42. Sherman MY, Qian SB. Less is more: improving proteostasis by translation slow down. Trends Biochem Sci. 2013;38:585-91.

43. Horn M, Nussbaumerová M, Sanda M, Kovárová Z, Srba J, Franta Z, et al. Hemoglobin digestion in blood-feeding ticks: mapping a multipeptidase pathway by functional proteomics. Chem Biol. 2009;16:1053-63.

44. Akov S, Samish M, Galun R. Protease activity in female Ornithodoros tholozani ticks. Acta Trop. 1976;33:37-52.

45. Hatta T, Kazama K, Miyoshi T, Umemiya R, Liao M, Inoue N, et al. Identification and characterisation of a leucine aminopeptidase from the hard tick Haemaphysalis longicornis. Int J Parasitol. 2006;36:1123-32.

46. Alim MA, Tsuji N, Miyoshi T, Islam MK, Hatta T, Fujisaki K. Legumains from the hard tick Haemaphysalis longicornis play modulatory roles in blood feeding and gut cellular remodelling and impact on embryogenesis. Int J Parasitol. 2009;39:97-107.

47. Hajdusek O, Sojka D, Kopacek P, Buresova V, Franta Z, Sauman I, et al. Knockdown of proteins involved in iron metabolism limits tick reproduction and development. Proc Natl Acad Sci U S A. 2009;106:1033-8.

48. Galay RL, Umemiya-Shirafuji R, Mochizuki M, Fujisaki K, Tanaka T. Iron metabolism in hard ticks (Acari: Ixodidae): the antidote to their toxic diet. Parasitol Int. 2015;64:182-9.

49. Hajdusek O, Almazán C, Loosova G, Villar M, Canales M, Grubhoffer L, et al. Characterization of ferritin 2 for the control of tick infestations. Vaccine. 2010:28:2993-8.

50. Galay RL, Miyata T, Umemiya-Shirafuji R, Maeda H, Kusakisako K, Tsuji N, et al. Evaluation and comparison of the potential of two ferritins as anti-tick vaccines against Haemaphysalis longicornis. Parasit Vectors. 2014;7:482.

51. Galay RL, Umemiya-Shirafuji R, Bacolod ET, Maeda H, Kusakisako K, Koyama J, et al. Two kinds of ferritin protect ixodid ticks from iron overload and consequent oxidative stress. PLOS ONE. 2014;9, e90661.

52. Galay RL, Aung KM, Umemiya-Shirafuji R, Maeda H, Matsuo T, Kawaguchi H, et al. Multiple ferritins are vital to successful blood feeding and reproduction of the hard tick Haemaphysalis longicornis. J Exp Biol. 2013;216:1905-15.

53. Dreher-Lesnick SM, Mulenga A, Simser JA, Azad AF. Differential expression of two glutathione S-transferases identified from the American dog tick, Dermacentor variabilis. Insect Mol Biol. 2006;15:445-53.
54. Lu J, Holmgren A. The thioredoxin antioxidant system. Free Radic Biol Med 2014;66:75-87.

55. Pacello F, Langford PR, Kroll JS, Indiani C, Smulevich G, Desideri A, et al. A novel heme protein, the $\mathrm{Cu}, \mathrm{Zn}$-superoxide dismutase from Haemophilus ducreyi. J Biol Chem. 2001;276:30326-34.

56. McMahon HT, Mills IG. COP and clathrin-coated vesicle budding: different pathways, common approaches. Curr Opin Cell Biol. 2004;16:379-91.

57. Owen DJ, Collins BM, Evans PR. Adaptors for clathrin coats: structure and function. Annu Rev Cell Dev Biol. 2004;20:153-91.

58. Sohn K, Orci L, Ravazzola M, Amherdt M, Bremser M, Lottspeich F, et al. A major transmembrane protein of Golgi-derived COPI-coated vesicles involved in coatomer binding. J Cell Biol. 1996;135:1239-48.

59. Dominguez M, Dejgaard K, Füllekrug J, Dahan S, Fazel A, Paccaud JP, et al gp25L/emp24/p24 protein family members of the cis-Golgi network bind both COP I and II coatomer. J Cell Biol. 1998;140:751-65.

60. Otto GP, Nichols BJ. The roles of flotillin microdomains-endocytosis and beyond. J Cell Sci. 2011;124:3933-40.

\section{Submit your next manuscript to BioMed Central and take full advantage of:}

- Convenient online submission

- Thorough peer review

- No space constraints or color figure charges

- Immediate publication on acceptance

- Inclusion in PubMed, CAS, Scopus and Google Scholar

- Research which is freely available for redistribution 